\title{
In-hospital mortality in people with complete acute traumatic spinal cord injury at a tertiary care center in India-a retrospective analysis
}

\author{
Harvinder Singh Chhabra (iD) ${ }^{\circledR}$, Rajesh Sharawat (D) $^{2}$ and Gayatri Vishwakarma (iD ${ }^{3}$ \\ (c) The Author(s), under exclusive licence to International Spinal Cord Society 2021
}

STUDY DESIGN: This is a retrospective study.

OBJECTIVES: To analyze the causes and risk factors of mortality in people admitted with complete acute traumatic spinal cord injury (ATSCI).

SETTING: The study was performed at the Indian Spinal Injuries Centre, New Delhi.

METHODS: Data between 2000 and 2016 were retrospectively collected from case records of people with ATSCI. Risk factors for mortality were examined using multivariable logistic regression.

RESULTS: Mortality rate in ATSCl admissions $(n=758)$ during the study period was $10 \%$. Median (IQR) age of study participants was 34 (21) years with a range of 14-85 years. Respiratory complications, septicemia, and cardiovascular causes were responsible for $42 \%, 28$, and $18 \%$ of deaths. Mortality rate in people with paraplegia and tetraplegia was $3 \%$ and $22 \%$, respectively. The proportion surviving at 6 weeks was significantly different across people with paraplegia and people with high and low tetraplegia $(p<0.001)$. Greater age (OR (multivariable models) $=1.03,95 \% \mathrm{Cl}=1.01-1.06)$, associated injuries $(\mathrm{OR}=2.42,95 \% \mathrm{Cl}=1.11-5.27)$, high tetraplegia $(O R=5.09,95 \% \mathrm{Cl}=2.21-11.72)$, low tetraplegia $(O R=4.84,95 \% \mathrm{Cl}=1.29-18.09)$, need for ventilator support $(\mathrm{OR}=$ $31.32,95 \% \mathrm{Cl}=14.92-65.35)$, septicemia $(\mathrm{OR}=4.60,95 \% \mathrm{Cl}=1.05-20.07)$, respiratory complications $(\mathrm{OR}=3.46,95 \% \mathrm{Cl}=$ 1.63-7.33), and cardiovascular causes $(\mathrm{OR}=39.03,95 \% \mathrm{Cl}=8.29-183.89)$ were significant risk factors associated with mortality. CONCLUSION: Respiratory complications, septicemia, and cardiovascular causes were the commonest causes of in-hospital mortality in people with complete ATSCI. Greater age, presence of associated injuries, tetraplegia, and ventilator support were risk factors significantly associated with mortality. To reduce morbidity and mortality in the acute phase, there is a need to focus on respiratory management and prevention of infections, especially in tetraplegics.

Spinal Cord (2022) 60:210-215; https://doi.org/10.1038/s41393-021-00657-x

\section{INTRODUCTION}

People with spinal cord injuries $(\mathrm{SCl})$ have a high risk of mortality [1] with studies documenting in-hospital mortality rates varying from 4 to $18 \%[2-6]$ in acute traumatic spinal cord injury (ATSCI). Even though the mortality rate during the initial days of hospitalization after ATSCl has gradually decreased with improvement in the acute care management systems [7], it still continues to be quite high in low- and middle-income countries (LMIC). According to a study by Chamberlain et al. [8], the combined in-hospital mortality in LMIC was nearly thrice that of high-income countries.

There have been no large retrospective or prospective studies on the causes of in-hospital mortality in ATSCI people. Reported principal causes of in-hospital death include respiratory dysfunction (36-83\%) [7, 9-12] and cardiovascular disorders (41\%) [13]. Pulmonary complications account for $80 \%$ of acute in-hospital mortality in people with tetraplegia [7]. Selassie et al. [6] documented a significant death rate within 120 days of ATSCI but did not document the causes of death. A study from India reported $48 \%$ of deaths within a week after sustaining the injury and $52 \%$ of deaths beyond a week [14]. This study included cases having isolated spine injuries and spinal injuries with associated trauma. However, the study focused more on the demographic profile of these people and timing of death since injury. Though causes of death and risk factors have been mentioned, they have not been discussed and analyzed appropriately. In a study by Hossain et al. studying 2-year survival following discharge from hospital after $\mathrm{SCl}$ in Bangladesh, causes of death prior to discharge in 21 people with ATSCI (respiratory: 62\%, pressure ulcer: 19\%, unknown: 19\%) have been mentioned [15]. However, no other details have been provided.

Several factors influence mortality in ATSCI [14, 16, 17]. However, few research studies have investigated the risk factors of mortality $[1,5,10,17]$. Important risk factors recognized by different studies on in-hospital mortality after ATSCI include advancing age, level of injury, type of injury, comorbidities, severe systemic injuries [17], complications such as venous

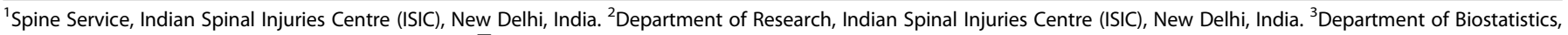
Indian Spinal Injuries Centre (ISIC), New Delhi, India. ${ }^{\circledR}$ email: drhschhabra@isiconline.org

Received: 24 July 2019 Revised: 12 June 2021 Accepted: 14 June 2021

Published online: 25 June 2021 
thromboembolism [17-19], and the hospital providing the acute care [6]. Promptly detecting the risk factors is critical to improve acute survival rates.

In India, limited information is available on demographics of $\mathrm{SCl}$ [19] and there is hardly any published literature on in-hospital mortality rates $[5,14]$. In fact, globally also information on in-hospital mortality in people with ATSCl is sparse and data are available mainly on long-term mortality [5]. The purpose of this study was to analyze the causes of in-hospital mortality as well as the associated risk factors in people with ATSCI at Indian Spinal Injuries Centre (ISIC).

\section{METHODS}

The study was performed at ISIC, a tertiary center in New Delhi, India, after approval from Institutional Research Review and Ethics Committees. People with ATSCI (with injury-admission interval $<30$ days) [8] with complete injury (American Impairment Scale (AIS) A as per International Standards of Neurological Classification of Spinal Cord Injury) who completed the comprehensive acute management were included in the study. Patients admitted beyond 30 days of their injury, re-admitted within 30 days of their injury, AIS B, C, D patients, and those who self-discharged early on without completing the comprehensive management were excluded. Data were retrospectively reviewed from 2748 medical records of people with $\mathrm{SCI}$ treated at the ISIC between 2000 and 2016. Of these, 758 were identified as people with ATSCI fulfilling the inclusion criteria. Information extracted from the medical records included demographic data (age, gender, mode of injury, dates of injury/admission/in-hospital death), injury-related data, associated injuries (head injury, chest/abdominal injuries, pelvic/limb injuries), vertebral level, neurological status (grouped into high (C1-C4)/low (C5-C8) tetraplegia and paraplegia), and length of hospital stay. Follow-up was only during the period of hospitalization required for comprehensive management or until inhospital death of people with ATSCl. Some other factors considered were number of direct (transferred from the site) or indirect admissions (transferred from other hospital), comorbidities (hypertension, history of chronic alcoholism, smoking, diabetes, bronchial asthma, coronary artery disease, cerebrovascular accident), complications (respiratory, pressure ulcers, deep vein thrombosis (DVT), urinary tract infection), ventilator dependency, and type of management (surgical/conservative) of the spinal injury. Comorbidities, complications, associated injuries, and causes of death were classified and defined as per International Classification of Diseases, 10th Revision [20] (see Supplementary Appendix 1 for list, definitions, and codes) and depicted in Supplementary Table S1. Also depicted are injury-admission interval table (Supplementary Table S2) and figure (Supplementary Fig. S1), a table on yearwise mortality presentation of data (Supplementary Table S3), studies looking into rate, causes, and predictors/risks of mortality within 1 year of spinal injury (Supplementary Table S4), and Cox proportional-hazard analysis adjusted for age and injury prior to the hospital admission showing risk factors with mortality rate at different time points (Supplementary Table S6).

\section{Statistical analysis}

Descriptive statistics for demographic variables were presented including graphical representation of mortality across people with paraplegia and tetraplegia. This was done using reverse Kaplan-Meier curves. The proportion surviving was compared across level of injury using $x^{2}$ test. A $p$ value less than 0.05 was considered to be statistically significant. The relationship between in-hospital mortality and mode of management as well as various risk factors including the mentioned comorbidities, associated injuries, age, gender, neurological status, and ventilator support was examined using univariate and multiple logistic regression. Variable selection for the model was done by using step-wise regression method. Odds ratio, with $95 \%$ confidence interval $(\mathrm{Cl}), C$ statistics, and $p$ value were presented in the final model. Concordance statistics is a measure of goodness of fit and is equal to the area under a receive operating characteristic curve for binary outcomes in a logistic regression model. Cox proportional-hazards regression analysis was used to relate several risk factors or exposures, considered simultaneously with survival time. Data analyses relied on SPSS version 23.0 software.

\section{RESULTS}

During the 16-year period (2000-2016) of the study, 758 people with ATSCI were hospitalized. Amongst these, 39\% (294) were
Table 1. Characteristics of persons with ATSCl.

\begin{tabular}{|c|c|c|c|}
\hline Variables & Total, $n$ (\%) & $\begin{array}{l}\text { Survived, } \\
n(\%)\end{array}$ & $\begin{array}{l}\text { Deceased, } \\
n(\%)\end{array}$ \\
\hline Total patients & $758(100)$ & $679(90)$ & $79(10)$ \\
\hline Age, median (range) & $34(14-80)$ & $32(14-80)$ & $48(14-80)$ \\
\hline \multicolumn{4}{|l|}{ Gender } \\
\hline Males & $679(85)$ & $581(86)$ & $65(10)$ \\
\hline Females & $112(15)$ & $98(88)$ & $14(13)$ \\
\hline \multicolumn{4}{|l|}{ Mode of injury } \\
\hline Road traffic accident & $334(44)$ & $299(69)$ & $35(11)$ \\
\hline Fall from height & $274(36)$ & $248(91)$ & $26(10)$ \\
\hline Others & $150(20)$ & $132(88)$ & $18(12)$ \\
\hline \multicolumn{4}{|c|}{ Neurological level of injury } \\
\hline $\begin{array}{l}\text { Cervical 1-4 (high } \\
\text { tetraplegia) }\end{array}$ & $46(6)$ & $36(78)$ & $10(22)$ \\
\hline $\begin{array}{l}\text { Cervical 5-8 (low } \\
\text { tetraplegia) }\end{array}$ & $248(33)$ & $194(78)$ & $54(22)$ \\
\hline $\begin{array}{l}\text { Thoracic/lumbar } \\
\text { (paraplegia) }\end{array}$ & $464(61)$ & 449 (97) & $15(3)$ \\
\hline \multicolumn{4}{|l|}{ Comorbidities } \\
\hline Hypertension & $31(4)$ & $25(4)$ & $6(8)$ \\
\hline Diabetes mellitus & $25(3)$ & $19(3)$ & $6(8)$ \\
\hline Smoking & $11(1)$ & $11(2)$ & $0(0)$ \\
\hline Alcohol & $12(2)$ & $10(1)$ & $2(3)$ \\
\hline $\begin{array}{l}\text { Ankylosing } \\
\text { spondylitis }\end{array}$ & $7(1)$ & $7(1)$ & $0(0)$ \\
\hline Anemia & $4(1)$ & $2(0)$ & $2(3)$ \\
\hline $\begin{array}{l}\text { History of previous } \\
\text { surgeries }\end{array}$ & $7(1)$ & $7(1)$ & $0(0)$ \\
\hline Asthma & $5(1)$ & $3(0)$ & $2(3)$ \\
\hline Epilepsy & $5(1)$ & $5(1)$ & $0(0)$ \\
\hline Thyroid & $3(0)$ & $3(0)$ & $0(0)$ \\
\hline Osteoporosis & $2(0)$ & $2(0)$ & $0(0)$ \\
\hline Miscellaneous & $9(1)$ & $9(1)$ & $0(0)$ \\
\hline \multicolumn{4}{|l|}{ Complications } \\
\hline Cardiovascular & $9(1)$ & $5(1)$ & $4(5)$ \\
\hline Respiratory & $96(13)$ & $67(10)$ & $29(37)$ \\
\hline Pressure ulcer & $41(5)$ & $38(6)$ & $3(4)$ \\
\hline $\begin{array}{l}\text { Deep vein } \\
\text { thrombosis }\end{array}$ & $11(1)$ & $10(1)$ & $1(1)$ \\
\hline $\begin{array}{l}\text { Urinary tract } \\
\text { infection }\end{array}$ & $11(1)$ & $11(2)$ & $0(0)$ \\
\hline Septicemia & $32(4)$ & $14(2)$ & $18(23)$ \\
\hline \multicolumn{4}{|l|}{ Type of management } \\
\hline Surgical & $562(74)$ & $519(92)$ & $43(7)$ \\
\hline Conservative & $196(26)$ & $160(82)$ & $36(18)$ \\
\hline \multicolumn{4}{|l|}{ Duration of stay } \\
\hline Median (range) & $40(0-535)$ & $43(0-535)$ & $16(0-203)$ \\
\hline $\begin{array}{l}\text { Associated injuries } \\
\text { (present) }\end{array}$ & $185(24)$ & $155(84)$ & $30(16)$ \\
\hline $\begin{array}{l}\text { Ventilator } \\
\text { dependency }\end{array}$ & $99(13)$ & $39(39)$ & $60(61)$ \\
\hline
\end{tabular}

tetraplegia, whereas $61 \%$ (464) were people with paraplegia. Table 1 summarizes demographic and clinical characteristics of study participants. A total of $85 \%$ (679) were males. Of the total ATSCl admissions, $10 \%$ (79) died while in hospital. Out of those who died, $82 \%$ were male and $81 \%$ were people with tetraplegia. Mortality rates in people with paraplegia and tetraplegia were 3\% and $22 \%$, respectively (Table 1 ). Median follow-up time and overall survival is depicted in Kaplan-Meier curve with number at risk (Fig. 1a) and reverse Kaplan-Meier curve (Fig. 1b). Median follow- 
(a)

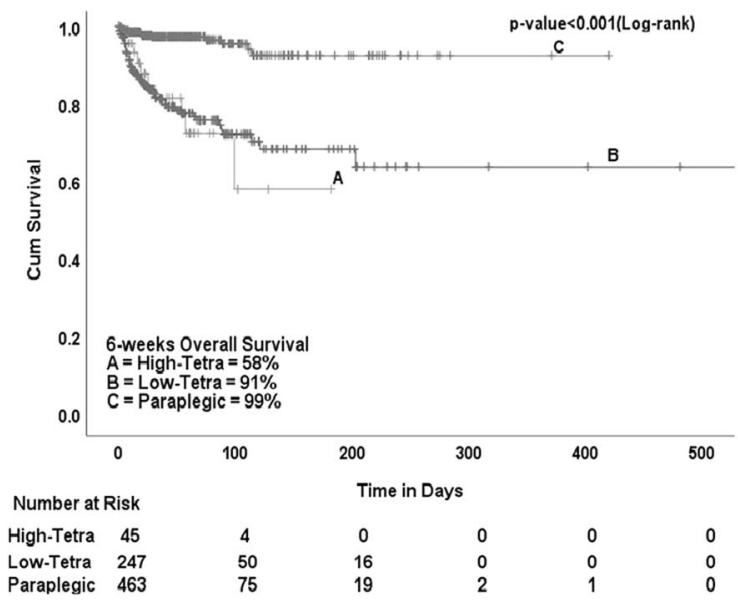

(b)

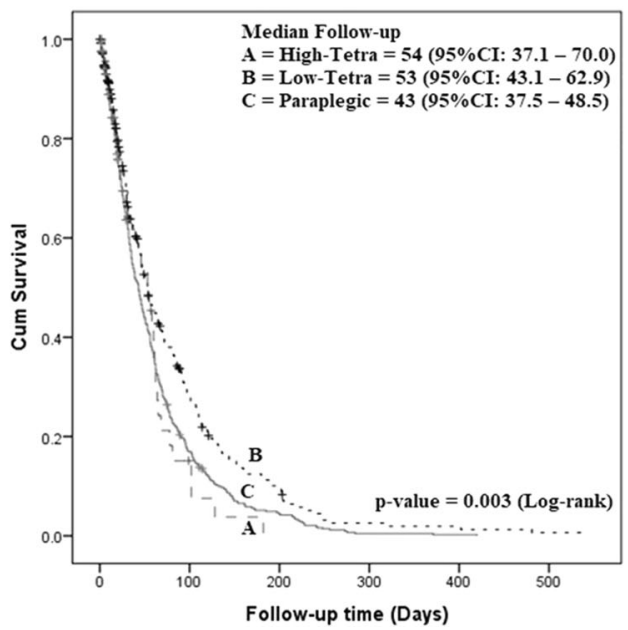

Fig. 1 Person with SCI were divided into three categories high tetraplegia, low tetraplegia, and paraplegia. a, b Kaplan-Meier curve and reverse Kaplan-Meier curve depicting mortality across high tetraplegia, low tetraplegia, and paraplegia. Median follow up and six-week overall survival were significantly different among the three groups.

up time was 54 days $(95 \% \mathrm{Cl}: 37-70)$ for people with high tetraplegia, 53 days (95\% Cl: 43-63) for people with low tetraplegia, and 43 days $(95 \% \mathrm{Cl}: 38-49)$ for people with paraplegia.

Six-week overall survival was significantly different among the three groups ( $p$ value $<0.001$ ), i.e., $58 \%$ in people with high tetraplegia, $91 \%$ in people with low tetraplegia, and $99 \%$ in people with paraplegia (Fig. 1a).

\section{Risk factors and causes of death}

Several significant factors that predict the risk of mortality in people with $\mathrm{ATSCl}$ as recognized by univariate logistic regression analysis are presented in Supplementary Table S5. With univariate analysis, which shows age (OR $(95 \% \mathrm{Cl})=1.05 \quad(1.03-1.06))$, neurological level of injury, i.e., high tetraplegia (OR $(95 \% \mathrm{Cl})=$ 8.33 (4.64-14.94)), low tetraplegia (OR $(95 \% \quad \mathrm{Cl})=8.31$ (3.49-19.83)) considering paraplegia as a reference, associated injuries $(\mathrm{OR}(95 \% \mathrm{Cl})=2.07(1.27-3.37))$ considering no associated injury as a reference, complications $(\mathrm{OR} \quad(95 \% \mathrm{Cl})=5.66$ (3.48-9.20)) considering no complications as a reference, type of management $(\mathrm{OR}(95 \% \mathrm{Cl})=2.72(1.69-4.38))$ considering surgery as a reference, cardiovascular causes (OR $(95 \% \mathrm{Cl})=11.08$ (3.30-37.19)), respiratory complications $(\mathrm{OR} \quad(95 \% \mathrm{Cl})=8.33$ $(5.01-13.83))$, septicemia (OR $(95 \% \mathrm{Cl})=6.88(2.95-16.08))$, and ventilator use $(\mathrm{OR}(95 \% \mathrm{Cl})=51.8(28.19-95.27))$ were found to be significant risk factors of mortality in ATSCl. Comorbidities (OR $(95 \% \mathrm{Cl})=1.84(0.99-3.46))$ considering no comorbidity as a reference did not show statistical significance, whereas diabetes mellietus (OR $(95 \% \mathrm{Cl})=2.86(1.11-7.37))$ and anemia (OR $(95 \%$ $\mathrm{Cl})=8.79(1.22-63.30))$ were found to be significant factors associated with in-hospital mortality univariately.

Multivariable logistic regression analysis showed that increasing age $(\mathrm{OR}(95 \% \mathrm{Cl})=1.03(1.01-1.06), p=0.004)$, level of injury [high tetraplegics (OR $(95 \% \mathrm{Cl})=5.09(2.21-11.72), p=0.019)$ and low tetraplegics (OR $(95 \% \mathrm{Cl})=4.84(1.29-18.09), p<0.001)]$, associated injuries (OR $(95 \% \mathrm{Cl})=2.42(1.11-5.27), p=0.027)$, ventilator support $(\mathrm{OR}(95 \% \mathrm{Cl})=32.99 \quad(15.66-69.51), p<0.001)$, cardiovascular causes (OR $(95 \% \mathrm{Cl})=39.03(8.29-183.89), p<$ $0.001)$, respiratory complications $(\mathrm{OR}(95 \% \mathrm{Cl})=3.46(1.63-7.33)$, $p=0.001)$, and septicemia (OR $(95 \% \mathrm{Cl})=4.60(1.05-20.07), p=$ 0.042 ) were risk factors having significant association with mortality (Table 2), whereas none of the comorbid conditions independently affected mortality and type of management (OR
Table 2. Multivariable logistic regression analysis of risk factors with in-hospital mortality.

\begin{tabular}{|c|c|c|c|}
\hline Variable & OR $(95 \% \mathrm{Cl})$ & $p$ value & C statistics \\
\hline Age & $1.03(1.01-1.06)$ & 0.017 & 0.955 \\
\hline \multicolumn{4}{|c|}{ Neurological level of Injury } \\
\hline Paraplegia & Ref. & & \\
\hline High tetraplegia & $5.09(2.21-11.72)$ & 0.019 & \\
\hline Low tetraplegia & $4.84(1.29-18.09)$ & $<0.001$ & \\
\hline Associated injuries & $2.42(1.11-5.27)$ & 0.027 & \\
\hline Ventilator use & $32.99(15.66-69.51)$ & $<0.001$ & \\
\hline \multicolumn{4}{|l|}{ Management } \\
\hline Operated & Ref. & 0.181 & \\
\hline Conservative & $1.66(0.79-3.51)$ & & \\
\hline \multicolumn{4}{|l|}{ Comorbidities } \\
\hline Diabetes mellitus & $1.06(0.21-5.47)$ & 0.944 & \\
\hline Anemia & $2.73(0.19-40.22)$ & 0.455 & \\
\hline \multicolumn{4}{|l|}{ Complications } \\
\hline Cardiovascular & $39.03(8.29-183.89)$ & $<0.001$ & \\
\hline Respiratory & $3.46(1.63-7.33)$ & 0.001 & \\
\hline Septicemia & $4.60(1.05-20.07)$ & 0.042 & \\
\hline
\end{tabular}

$O R$ odds ratio.

Bold values indicate statistical significance at $5 \%$.

$(95 \% \mathrm{Cl})=1.66(0.79-3.51), p=0.181)$ was not found to be statistically significant risk factor. $C$ statistic was also calculated for multivariate model and found to be 0.786 (Table 4).

Supplementary Table S6 shows univariate analysis for subgroups of associated injury, i.e., multiple, single and no injury. Results revealed that both types of associated injuries, i.e., single $(\mathrm{OR}=1.76,95 \% \mathrm{Cl}: 1.03-3.01, p=0.040)$ and multiple $(\mathrm{OR}=4.07$, $95 \% \mathrm{Cl}: 1.72-9.68, p=0.001)$ are significantly associated with mortality.

As depicted in Table 3, the most frequent cause of death was respiratory complications (42\%) comprising mainly of pulmonary embolism (22\%) and chest infection (14\%). The second most common cause of death was septicemia, (28\%) followed by 
Table 3. Causes of death.

\begin{tabular}{|c|c|c|c|c|c|}
\hline & \multirow[t]{2}{*}{ Cause } & \multicolumn{3}{|l|}{ Level } & \multirow{2}{*}{$\begin{array}{l}\begin{array}{l}\text { Total } \\
\text { deceased }\end{array} \\
n=79(\%)\end{array}$} \\
\hline & & $\begin{array}{l}\text { Paraplegics } \\
n=16 ; \\
56.3 \%\end{array}$ & $\begin{array}{l}\text { High } \\
\text { tetraplegics } \\
n=10 ; \\
12.7 \%\end{array}$ & $\begin{array}{l}\text { Low } \\
\text { tetraplegics } \\
n=53 ; \\
67.1 \%\end{array}$ & \\
\hline \multirow{4}{*}{$\begin{array}{l}\text { Respiratory } \\
\text { complications }\end{array}$} & Pulmonary embolism & $6(38)$ & $1(10)$ & $10(19)$ & $17(22)$ \\
\hline & Chest infection & $2(13)$ & $1(10)$ & $8(15)$ & $11(14)$ \\
\hline & Acute respiratory distress syndrome & $1(6)$ & $1(10)$ & $2(4)$ & $4(5)$ \\
\hline & Aspiration & $1(6)$ & & $0(0)$ & $1(1)$ \\
\hline \multirow[t]{3}{*}{ Other } & Septicemia & $2(13)$ & $2(20)$ & $18(34)$ & $22(28)$ \\
\hline & Cardiovascular causes & $0(0)$ & $5(50)$ & $9(17)$ & $14(18)$ \\
\hline & Miscellaneous & $4(25)$ & $0(0)$ & $6(11)$ & $10(13)$ \\
\hline
\end{tabular}

Table 4. Cox proportional-hazard analysis showing risk factors with survival time.

\begin{tabular}{|c|c|c|c|c|c|c|c|}
\hline \multirow[t]{2}{*}{ Characteristics } & \multirow[t]{2}{*}{ B } & \multirow[t]{2}{*}{ SE } & \multirow[t]{2}{*}{ Hazard ratio (HR) } & \multicolumn{2}{|l|}{$95 \% \mathrm{Cl}$} & \multirow[t]{2}{*}{$p$ value } & \multirow[t]{2}{*}{ Harrell's C statistic } \\
\hline & & & & Lower & Upper & & \\
\hline Age & 0.02 & 0.01 & 1.02 & 1.001 & 1.032 & 0.031 & 0.786 \\
\hline Associated injuries & 0.54 & 0.24 & 1.72 & 1.072 & 2.767 & 0.031 & \\
\hline Ventilator use & 2.67 & 0.28 & 14.44 & 8.310 & 25.073 & $<0.001$ & \\
\hline \multicolumn{8}{|l|}{ Level } \\
\hline High tetraplegia & 1.421 & 0.41 & 4.14 & 1.839 & 9.319 & 0.001 & \\
\hline Low tetraplegia & 1.24 & 0.31 & 3.44 & 1.876 & 6.322 & $<0.001$ & \\
\hline
\end{tabular}

The bold value represents statistical significance at $5 \%$ level.

cardiovascular causes (18\%). Other documented causes of death (13\%) were hematemesis, dengue with hemorrhagic shock, fat embolism, renal failure, fulminating varicella zoster infection, and enteric perforation.

Furthermore, in Cox proportional-hazard model (Table 4) adjusted for age and injury time prior to the hospital admission, an increased risk of mortality was observed with associated injuries $(\mathrm{HR}(95 \% \mathrm{Cl})=1.72(1.07-2.77))$ as compared to no associated injuries and with ventilator use (HR $(95 \% \mathrm{Cl})=14.44$ (8.31-25.07)) as compared to no ventilator use. Similarly, an increased risk of mortality was found with high tetraplegia (HR $(95 \% \mathrm{Cl})=4.14(1.84-9.34))$ and low tetraplegia $(\mathrm{HR}(95 \% \mathrm{Cl})=$ $3.44(1.87-6.32))$ as compared to paraplegia. Hence, people with ATSCl having associated injuries were at $73 \%$ more risk of mortality per day than those having no associated injuries. Also, those on a ventilator were 14 times more at risk of mortality per day than those not on a ventilator. People with high and low tetraplegia were four and three times more at risk of mortality per day, respectively, as compared to people with paraplegia.

Both multivariable logistic regression analysis and Cox proportional-hazards regression analysis revealed that associated injuries, ventilator use, and cervical level of injuries were the significant risk factors of in-hospital mortality in people with ATSCI. Also, Cox proportional-hazard analysis was done after adjusting for age and injury prior to the hospital admission to identify the risk factors with mortality rate at 30-, 60-, and 90-day time points (Supplementary Table S7). Various risk factors such as ventilator use, level of injury, associated injuries, septicemia, and cardiovascular factors influenced the mortality amongst the three groups at 90 days. Characteristics of the patients who stayed more than a year are presented in Supplementary Table S8. Four of these were tetraplegics whereas one was paraplegic, three patients had complications and one was ventilator dependent. One patient with tetraplegia was managed conservatively and had a prolonged stay in the hospital for 535 days.

\section{DISCUSSION}

This study investigates the causes of in-hospital mortality as well as the associated risk factors in patients with ATSCI (injuryadmission interval $<30$ days) who had undergone treatment at one center over a 16-year period.

In our study, the mortality rate was $10.4 \%$. The limited studies available on in-hospital mortality have shown mortality rates of 4-18\% [2-6]. The other Indian study [14] could not assess mortality rates as the study analyzed data from autopsy cases/ case records of people with $\mathrm{SCl}$ who died.

Males constituted a high percentage of the deceased in our study. This is understandable since males also constituted $85 \%$ of the spinal injured cohort. Other available studies also had a similar observation [1, 8, 10, 21, 22].

Studies have found a higher incidence of deaths in people with tetraplegia (80\%) than people with paraplegia (20\%) probably due to the respiratory compromise in people with tetraplegia [11, 23]. Similarly, mortality rate was quite high in people with tetraplegia as compared to people with paraplegia in our study. The mortality rate amongst people with high and low tetraplegia was almost similar.

Respiratory dysfunction is the principle cause of in-hospital mortality [9] with an incidence of $36-83 \%$ [7, 10-12]. This holds particularly true for people with tetraplegia where pulmonary complications account for up to $80 \%$ of acute in-hospital mortality $[7,24]$. Our study also corroborated that respiratory complications 
are the most frequent underlying cause of death (41.8\%). It is now established that specialized respiratory care is effective in improving respiratory status [8] and this stresses the importance of respiratory management, especially in tetraplegia and a special respiratory unit for monitoring and managing $\mathrm{SCl}$ patients. Even though this has been especially recommended for high cervical cord injuries [12], the findings of our study suggest that a special respiratory unit would add value to all patients with cervical spine injuries.

Despite appropriate prophylaxis, pulmonary embolism continues to contribute significantly to morbidity and mortality after $\mathrm{SCl}$. In a review article by Hagen et al. (page no. 5), "the incidence of pulmonary embolism was $15 \%$ and there was mortality rate of $1 \%$ in the first year of the injury" [16]. Our study found pulmonary embolism to be one of the main causes (22\%) of mortality. Other studies have documented pulmonary embolism as the cause of mortality in $23 \%$ [18] and $4 \%$ [6] of ATSCl, respectively.

Chest infection is another respiratory complication quite common after ATSCI. DeVivo et al. [21] reported an incidence of $18 \%$. Durga et al. [5] reported a high significant coefficient correlation of $0.56(p=0.00)$ between respiratory infections and mortality. Our study showed that respiratory infections are a common cause of death (14\%) as well.

In our study, septicemia was the second most common cause (28\%) of death. In the other Indian study [14] sepsis was the main cause of death (72\%). Unfortunately, there is no other study that has reported the percentage of in-hospital mortality due to septicemia in ATSCI. In long-term mortality studies, septicemia due to infections from infected decubiti, urinary tract infection, and pneumonitis has been a primary cause of death [21]. In the study by DeVivo et al. [21], septicemia accounted for $10 \%$ of all deaths after the first year of injury.

Cardiovascular disorders $[12,25]$ are also amongst the principle causes of mortality in the acute phase of ATSCI. In the other Indian study [14], hemodynamic instability was the cause of death in $11 \%$ of cases [16, 26-29]. In our study, cardiovascular cause was the third leading cause (18\%) of in-hospital mortality in ATSCI. Labile cardiac activity, bradycardia, and hypoxia have been together observed to precede episodes of cardiac arrest. Mortality can be reduced by due attention to these red flags of impending cardiovascular causes. Bradycardia is also influenced by cervical $\mathrm{SCl}$, hypoxia, and endotracheal suction [30]. The respiratory complications in people with acute tetraplegia with the consequent hypoxia are assumed to account for the higher frequency of bradycardia in these patients. Hence, oxygen therapy has been advocated prior to endotracheal suction. In addition, anticholinergic or vasopressor support may be required to stabilize the cardiovascular system [31].

In the other Indian study [14], head injury and neurogenic shock were amongst the other cause of death in $15.8 \%$ and $1.2 \%$ cases, respectively. Other causes of death in our study were hematemesis, dengue with hemorrhagic shock, fat embolism, renal failure, fulminating varicella zoster infection, and enteric perforation in $12.7 \%$ of cases. Our study also studied the risk factors associated with in-hospital mortality in people with ATSCI. Like in the study by Selassie et al. [17], greater age was a risk factor significantly associated with in-hospital mortality in our study as well.

Presence of associated injuries [32] defined as coinjury to head, chest, abdomen, pelvis, and limb has also been found to be a significant factor influencing mortality in our as well as other studies $[17,33,34]$.

Subgroup analysis for associated injury, i.e., multiple, single, and no injury shows significant association with mortality. Association with mortality in multiple associated injuries is four times while in single associated injury it is two times. Ventilator dependency $[5,9]$ has been similarly implicated. In a study done to develop a predictive score for ventilator requirement and in-hospital mortality of people with cervical spine injury (predictors of respiratory insufficiency and mortality), mechanical ventilation was an independent predictor of mortality [3].

Coexisting comorbidities and type of management were the other risk factors that were studied. These were not found to be significant. In some in-hospital studies, coexisting comorbidities were found to be highly associated with mortality $[6,17]$. In one of these studies, comorbid conditions and concomitant injury collectively had stronger effect on mortality [6]. In our study, comorbidities were seen in only $14(16.5 \%)$ of the deceased. Coexisting comorbidities generally manifest and influence health status with advancing age. In our study, the average age of the deceased subjects was lower (46.6 years) than the other study (59.3 years) [6] in which comorbidities were associated with mortality. This could explain the difference in findings in the two studies.

Similar to a study by Li et al. [35], we found no correlation of mortality with type of management in ATSCl. Modern methods of anesthesia and intensive care trauma management including respiratory and hemodynamic resuscitation have allowed ATSCI patients to go through surgery safely with minor differences in complication rates between surgical and conservative groups $[5,17]$.

Our study emphasizes on the need to improve the respiratory care in people with $\mathrm{SCl}$ and specifically those with cervical cord injuries. Studies on early mortality suggest that older age and complete injuries increase the risk of mortality globally. This study had various strengths. It may represent the LMIC scenario and hence a significant global population. It is also perhaps the first comprehensive study assessing the causes of in-hospital mortality in patients with ATSCI in a spinal injury center over a 16-year period. The only other published study, also from India, focused more on the demographic profile and timing of death since injury. The causes of death and risk factors have not been discussed and analyzed appropriately. Another study from Bangladesh on 2-year survival post discharge mentions causes of death in 21 patients before discharge but no relevant details have been provided.

\section{LIMITATIONS}

This study had the limitations associated with any retrospective study including controlling any confounding variables. The study was limited to assessing in-hospital mortality and not the longterm mortality. Only complete injuries were studied. Since the study represents a LMIC scenario, the findings may not be applicable globally. Injury severity scale (ISS) and better still New Injury Severity Score, as well as non-use of DVT prophylaxis have shown to be predictors of in-hospital mortality but these could not be documented in our study. The cause could also not be confirmed by autopsy in all cases. The risk of mortality could be influenced by general health conditions and socioenvironmental factors but these could not be documented in our study. Due to the limited number of patients who had comorbidities $(11 \%$ of the sample), it is difficult to draw meaningful conclusion from univariate and multivariate analysis. Amongst the other limitations, the duration of ventilator support as a risk factor for mortality and the impact of timing of complication on in-hospital mortality could not be analyzed. Though it would have been useful to analyze the effect of calendar year in the model to adjust for temporal changes in hospital practice, since it was a retrospective study collecting data for the last 16 years and the hospital practice for each year in this duration had not been documented, this could not be done.

\section{CONCLUSIONS}

Respiratory complications, septicemia, and cardiovascular causes were the leading causes of in-hospital mortality in complete ATSCI in our study. Tetraplegia and ventilator dependency were the strongest 
predictors of mortality followed by greater age and presence of associated injuries. There is a need to focus on respiratory management and prevention of infections in people with tetraplegia in the acute phase to reduce morbidity and mortality and this should be a major thrust area for further research.

\section{DATA AVAILABILITY}

The datasets generated during and/or analyzed during the current study are not publicly available in order to maintain patient confidentiality but are available from the corresponding author on reasonable request.

\section{REFERENCES}

1. Krause JS, Saunders LL, Zhai Y. Stability of predictors of mortality after spinal cord injury. Spinal Cord. 2012;50:281-4.

2. Pickett GE, Campos-Benitez M, Keller JL, Duggal N. Epidemiology of traumatic spinal cord injury in Canada. Spine (Phila Pa 1976). 2006;31:799-805.

3. Kattail D, Furlan JC, Fehlings MG. Epidemiology and clinical outcomes of acute spine trauma and spinal cord injury: experience from a specialized spine trauma center in Canada in comparison with a large national registry. J Trauma. 2009;67:936-43.

4. Mansfield K, Meyer K, Ugiliweneza B, Nosova K, Boakye M. Traumatic spinal cord injury with concomitant brain injury: in-hospital complication rates and resource utilization. JSM Neurosurg Spine. 2014;2:1017.

5. Durga P, Sahu BP, Mantha S, Ramachandran G. Development and validation of predictors of respiratory insufficiency and mortality scores: simple bedside additive scores for prediction of ventilation and in-hospital mortality in acute cervical spine injury. Anesth Analg. 2010;110:134-40.

6. Selassie AW, Varma A, Saunders LL, Welldaregay W. Determinants of in-hospital death after acute spinal cord injury: a population-based study. Spinal Cord. 2012;51:48-54.

7. Berlly $M$, Shem K. Respiratory management during the first five days after spinal cord injury. J Spinal Cord Med. 2007;30:309-18.

8. Chamberlain JD, Meier S, Mader L, von Groote PM, Brinkhof MWG. Mortality and longevity after a spinal cord injury: systematic review and meta-analysis. Neuroepidemiology. 2015;44:182-98.

9. Brown R, DiMarco AF, Hoit JD, Garshick E. Respiratory dysfunction and management in spinal cord injury. Respir Care. 2006;51:853-68. Discussion 869-70.

10. Cao Y, Krause JS, DiPiro N. Risk factors for mortality after spinal cord injury in the USA. Spinal Cord. 2013;51:413-8.

11. Grossman RG, Frankowski RF, Burau KD, Toups EG, Crommett JW, Johnson MM, et al. Incidence and severity of acute complications after spinal cord injury. J Neurosurg Spine. 2012;17(Suppl):119-28.

12. Casha S, Christie S. A systematic review of intensive cardiopulmonary management after spinal cord injury. J Neurotrauma. 2011;28:1479-95.

13. Garshick E, Kelley A, Cohen SA, Garrison A, Tun CG, Gagnon D, Brown R. Original article: a prospective assessment of mortality in chronic spinal cord injury. Spinal Cord. 2005;43:408-16.

14. Lalwani S, Singh V, Trikha V, Sharma V, Kumar S, Bagla R, et al. Mortality profile of patients with traumatic spinal injuries at a level I trauma care centre in India. Indian J Med Res. 2014;140:40-5. http://www.pubmedcentral.nih.gov/ articlerender.fcgi?artid=4181158\&tool=pmcentrez\&rendertype $=$ abstract.

15. Hossain M, Rahman M, Herbert R, Quadir M, Bowden J, Harvey L. Two-year survival following discharge from hospital after spinal cord injury in Bangladesh. Spinal Cord. 2016;54:132-6.

16. Hagen EM, Rekand T, Gronning M, Faerestrand S. Cardiovascular complications of spinal cord injury. Tidsskr Nor Laegeforen. 2012;132:1115-20.

17. Varma A, Hill EG, Nicholas J, Selassie A. Predictors of early mortality after traumatic spinal cord injury: a population-based study. Spine (Phila Pa 1976). 2010;35:778-83

18. Waring WP, Karunas RS. Acute spinal cord injuries and the incidence of clinically occurring thromboembolic disease. Paraplegia. 1991;29:8-16.

19. Chhabra HS, Arora M. Demographic profile of traumatic spinal cord injuries admitted at Indian Spinal Injuries Centre with special emphasis on mode of injury: a retrospective study. Spinal Cord. 2012;50:745-54.

20. WHO. International Statistical Classification of Diseases and Related Health Problems ICD10, 2. WHO Press; 2010.

21. DeVivo MJ, Krause JS, Lammertse DP. Recent trends in mortality and causes of death among persons with spinal cord injury. Arch Phys Med Rehabil. 1999:80:1411-9.

22. Tator CH, Duncan EG, Edmonds VE, Lapczak LI, Andrews DF. Neurological recovery, mortality and length of stay after acute spinal cord injury associated with changes in management. Paraplegia. 1995;33:254-62.
23. Neumann CR, Brasil AV, Albers F. Risk factors for mortality in traumatic cervical spinal cord injury: Brazilian data. J Trauma - Inj Infect Crit Care. 2009;67:67-70.

24. Reines HD, Harris RC. Pulmonary complications of acute spinal cord injuries. Neurosurgery. 1987;21:193-6.

25. Rabadi MH, Mayanna SK, Vincent AS. Predictors of mortality in veterans with traumatic spinal cord injury. Spinal Cord. 2013;51:784-8.

26. Lehmann KG, Lane JG, Piepmeier JM, Batsford WP. Cardiovascular abnormalities accompanying acute spinal cord injury in humans: incidence, time course and severity. J Am Coll Cardiol. 1987;10:46-52. http://www.ncbi.nlm.nih.gov/pubmed/ 3597994.

27. Franga DL, Hawkins ML, Medeiros RS, Adewumi D. Recurrent asystole resulting from high cervical spinal cord injuries. Am Surg. 2006;72:525-9.

28. Bartholdy K, Biering-Sørensen T, Malmqvist L, Ballegaard M, Krassioukov A, Hansen $B$, et al. Cardiac arrhythmias the first month after acute traumatic spinal cord injury. J Spinal Cord Med. 2014;37:162-70.

29. Sabre L, Rekand T, Asser T, Körv J. Mortality and causes of death after traumatic spinal cord injury in Estonia. J Spinal Cord Med. 2013;36:687-94.

30. Frankel H. Mechanisms of reflex cardiac arrest in tetraplegic patients. Lancet. 1975;306:1183-5.

31. Piepmeier JM, Lehmann, KB, Lane JG. Cardiovascular instability following acute cervical spinal cord trauma. Cent Nerv Syst Trauma. 1985;2:153-60. https://www. ncbi.nlm.nih.gov/labs/articles/3835007/.

32. Chu D, Lee $\mathrm{Y}-\mathrm{H}$, Lin $\mathrm{C}-\mathrm{H}$, Chou $\mathrm{P}$, Yang N-P. Prevalence of associated injuries of spinal trauma and their effect on medical utilization among hospitalized adult subjects-a nationwide data-based study. BMC Health Serv Res. 2009;9:137.

33. Myers J, Lee M, Kiratli J. Cardiovascular disease in spinal cord injury. Am J Phys Med Rehabil. 2007;86:142-52.

34. Daverat P, Gagnon M, Dartigues JF, Mazaux JM, Barat M. Initial factors predicting survival in patients with a spinal cord injury. J Neurol Neurosurg Psychiatry. 1989;52:403-6.

35. Li Y, Walker CL, Zhang YP, Shields CB, Xu X-M. Surgical decompression in acute spinal cord injury: a review of clinical evidence, animal model studies, and potential future directions of investigation. Front Biol (Beijing). 2014;9:127-36.

\section{ACKNOWLEDGEMENTS}

We appreciate the contribution of Dr Mihir Niyogi in data extraction. We also thank Dr Karthik Yelamarthy, Dr Ashok Reddy, and Dr Vandana Phadke for providing insightful comments in improving the manuscript. No financial assistance was received in support of this study.

\section{AUTHOR CONTRIBUTIONS}

HSC was responsible for the designing the study protocol, analyzing data, and writing the report. RS was responsible for conducting the search, screening potentially eligible studies, extracting and analyzing data, and writing the report. GV was responsible for analyzing data, interpreting results, and creating tables as well as figures.

\section{COMPETING INTERESTS}

The authors declare no competing interests.

\section{ETHICS STATEMENT}

We certify that all applicable institutional and governmental regulations concerning the ethical use of human volunteers were followed during the course of this research.

\section{ADDITIONAL INFORMATION}

Supplementary information The online version contains supplementary material available at https://doi.org/10.1038/s41393-021-00657-x.

Correspondence and requests for materials should be addressed to H.S.C.

Reprints and permission information is available at http://www.nature.com/ reprints

Publisher's note Springer Nature remains neutral with regard to jurisdictional claims in published maps and institutional affiliations. 